\title{
Electrochemical Tailoring of Honeycomb-Structured ZnO Thin Films by Interfacial Surfactant Templating
}

\author{
B. G. Pawar, P. P. Salvi, and S. S. Kolekar \\ Material Science and Electrochemistry Research Laboratory, Department of Chemistry, Shivaji University, Kolhapur 416004, India
}

Correspondence should be addressed to S. S. Kolekar, pawarbg12@rediffmail.com

Received 29 April 2012; Accepted 18 June 2012

Academic Editors: J. Elias, P. Kumbhakar, H. Usui, and R. Wahab

Copyright () 2012 B. G. Pawar et al. This is an open access article distributed under the Creative Commons Attribution License, which permits unrestricted use, distribution, and reproduction in any medium, provided the original work is properly cited.

Zinc oxide thin films with honeycomb structures can be electrochemically produced by interfacial surfactant templating. Newly synthesized 4-amino-1-(2,3-dihydroxy propyl) pyridinium hydroxide ionic liquid exhibiting the hydroxyl functionalized ionic liquids (HFILs) was used in electrodeposition. This method utilizes amphiphile assemblies at the solid-liquid interface (i.e., the surface of a working electrode) as a template to gain the precisely tailor zinc oxide nanostructures. The results described here will provide a useful foundation to design and optimize greener protocol for the electrochemical construction of inorganic nanostructures thin films for possible application of films in nanotechnology field. Moreover, it is believed that this electrochemical tailoring approach can be extended to fabricate other porous metal oxide materials with a unique morphology or shape.

\section{Introduction}

Recently, ionic liquids (ILs) created a center of attention due to their unique materials and solvent properties and the growing interest in academia as well as applicative purposes. Salts with organic cations open a window for the liquid state at more moderate temperatures. Adopting such ideas, the past decade has seen the advent of a new class of solvents, referred to as "ionic liquids". This term describes organic salts that are liquid at or near room temperature which have melting point below some arbitrary temperature, such as $100^{\circ} \mathrm{C}[1]$. The unique properties of ILs such as high conductivity, nonvolatility, low toxicity, large electrochemical window, good electrochemical stability, and high ionic mobility favor its applications in diverse fields, such as synthesis, catalysis, separation technology, electrochemistry, analytical chemistry, and nanotechnology [2]. But the highly viscous nature of ILs has low ionic conductivity at room temperature, which inevitably affects their performance. Therefore, designing an IL with high conductivity and a large voltage window for practical applications is still challenging. The unique variability of the ions often allows the properties of interest to be imparted, so that ILs are denoted as "designer solvents" or "task-specific ionic liquids (TSILs)", which can solve the regarding problems.

Recently, much advancement of zinc oxide nano- and microstructure with various applications [3-8], is because zinc oxide $(\mathrm{ZnO})$ is a versatile material of compound semiconductors with excellent properties and extensive applications in electronics, photoelectronics, sensors, and catalyses. The remarkable properties of $\mathrm{ZnO}$ are its wide direct-band gap of $3.37 \mathrm{eV}$ and high-exciton-binding energy of $60 \mathrm{mV}$ at room temperature. Nanomaterials of $\mathrm{ZnO}$ with onedimensional structures such as nanowires, nanowhiskers, nanotubes, nanobelts, and nanorods have been intensively studied for applications of opto-electronic devices in nanoscale because the optical and electronic properties in these nanostructures are enhanced by the quantum confinement effect [9-13]. Different methods have been put forward to prepare $\mathrm{ZnO}$ including chemical vapour deposition (CVD), thermal oxidation, radiofrequency magnetron sputtering, pulsed laser deposition, electron beam evaporation, spray pyrolysis, and electrodeposition [14-19]. Among them, electrodeposition from aqueous solution is uncomplicated, environmentally friendly, and low-cost technique by which uniform film with controlled stoichiometry 
can be produced due to this, many efforts on electrodeposition of $\mathrm{ZnO}$ films are reported [20-28]. However, only a few works are focused on interfacial surfactant templating. In 2002, nanostructured $\mathrm{ZnO}$ films were utilizing selfassembly of surfactant molecules at solid-liquid interfaces. This method utlizes cetyl trimethylammonium bromide (CTAB) or anionic surfactant, sodium dodecyl sulfate (SDS) [29]. In 2005, lamellar-structured $\mathrm{ZnO}$ films by interfacial surfactant templating, utilizes amphiphile assemblies at the solid-liquid interface surfactants with anionic headgroups (e.g., 1-hexadecanesulfonate sodium salt, dodecylbenzenesulfonate sodium salt, dioctyl sulfosuccinate sodium salt, mono-dodecyl phosphate, and sodium dodecyl sulfate), are critical because they incorporate $\mathrm{Zn}^{2+}$ ions into their bilayer assemblies as counterions and guide the lamellar growth of $\mathrm{ZnO}$ films [30].

Therefore, to increase the control of electrochemical interfacial surfactant templating, we investigated potential usefulness of newly synthesized 4-amino-1-(2,3-dihydroxy propyl) pyridinium, hydroxide $[\mathrm{ADPPY}][\mathrm{OH}]$ ionic liquid. This is the first report on interfacial surfactant templating by $[\mathrm{ADPPY}][\mathrm{OH}]$ ionic liquid producing honey comb structured zinc oxide. Consequently, these results will provide a useful foundation to design/optimize synthetic conditions for broader types of inorganic nanostructures with different morphology for technological application.

\section{Experimental}

2.1. Synthesis of Ionic liquid. The TSIL, 4-amino-1-(2,3dihydroxy propyl) pyridinium, hydroxide was synthesized by our reported procedure [31] (See Figure 5).

Electrochemical tailoring of zinc oxide: the zinc oxide thin films were prepared potentiostatically. The electrolyte used for deposition of zinc oxide consists of a $0.1 \mathrm{M}$ TSILs and $0.1 \mathrm{M}$ zinc chloride. The electrodeposition was performed potentiostatically at a potential difference of $1.9 \mathrm{~V}$ with respect to SCE (saturated calomel electrode) at room temperature. The electrochemical tailoring of zinc oxide was made in the compartment; is consists of three electrode system with electrolyte; the graphite was the counter electrode; the indium doped tin-oxide-(ITO-) coated glass substrates were working electrode, and SCE (saturated calomel electrode) was the reference electrode. All the voltages were measured with respect to SCE. Deposition was made at room temperature with varying the deposition time from $30 \mathrm{sec}$ to $600 \mathrm{sec}$.

2.2. Materical Characterization. The thickness of $\mathrm{ZnO}$ thin film was measured by surface profiler AMBIOS (XP-1) unit. The structural analysis was carried out using Brukar axs D8 advanced X-ray diffractometer (XRD) within the range $20-60^{\circ} \mathrm{C}$ on computer controlled $\mathrm{Cu}-\mathrm{K} \alpha$ radiations source. The microstructure of the film was observed using Scanning Electron Microscopy (SEM). The wettability of the films was evaluated by measuring the contact angle $(\theta)$ of a water droplet of $10 \mu \mathrm{L}$ placed on the film surface using the contact angle meter equipped with a CCD camera (Ramehart

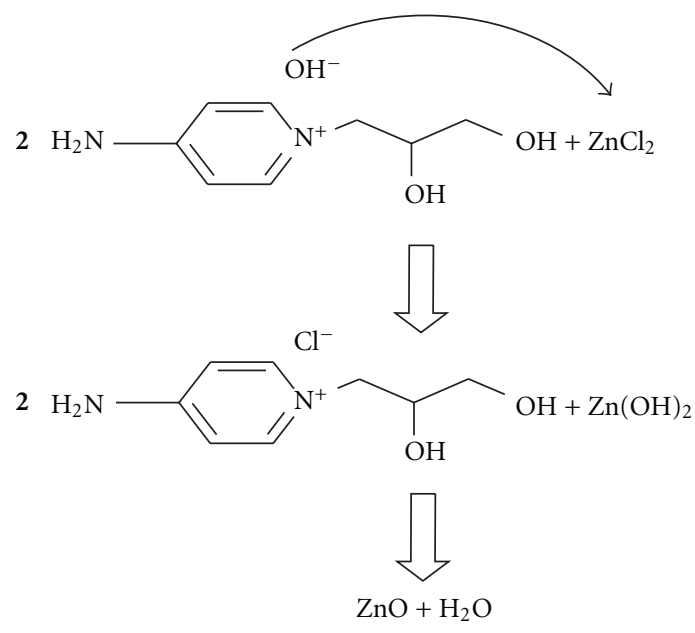

Scheme 1: Plausible mechanism for $\mathrm{ZnO}$.

Instrument Co., USA) at an ambient temperature. The photo luminance study was carried out on spectrofluorimeter 2000 model.

\section{Results and Discussion}

Solid-liquid interfaces provide a unique environment for surfactant assembly [32]. Micelles can form at the interface even when the surfactant concentration is lower than the critical micelle concentration $(\mathrm{cmc})$ due to surface forces. The assembly patterns of the surface aggregates are mainly determined by the substrate properties (i.e., hydrophobicity, surface charge density) and are frequently different from those in free solution [33]. This makes it possible to separately control the surfactant assembly at the interface by applying a bias voltage to the substrate and tuning the surface charge densities. TSIL [ADPPY] $[\mathrm{OH}]$ constructed by [ADPPY] that is, 4-aminopyridinium dihydroxy butane functionalized cation and $[\mathrm{OH}]$ anion. In the formation of $\mathrm{ZnO}$, anion that is, $\mathrm{OH}^{-}$plays crucial role, in the formation of zinc hydroxide [34]. $\mathrm{Zn}^{2+}$ combines with two molecules of $[\mathrm{OH}]$ anion of the ionic liquid and forms hydroxide, as shown in Scheme 1. An important point is to understand the deposition solution chemistry and especially the zinc species involved in the deposition process. In aqueous solution, $\mathrm{Zn}$ (II) soluble species are $\mathrm{Zn}^{2+}$ and hydroxide or chloride complexes. Considering the structural aspects of the ionic liquids is usually helpful for the rationalization of physical and chemical processes occurring in the RTILs. In RTILs, there is a complex interplay of forces (Coulombic, van der Waals (dipole-dipole, dipole-induced dipole, dispersion), hydrogen bond, and possible $\pi-\pi$ or $n-\pi$ stacking), which controls the solvation and is the dominant stabilizing force, but the charge transfer and orbital interaction can contribute significantly [35]. The possible $\mathrm{ZnO}$-IL-coordination is shown in Scheme 3. We expect that the unique mechanisms of electrochemical interfacial surfactant templating for building organic assemblies and inorganic frameworks will broaden the type of inorganic materials that can be produced 


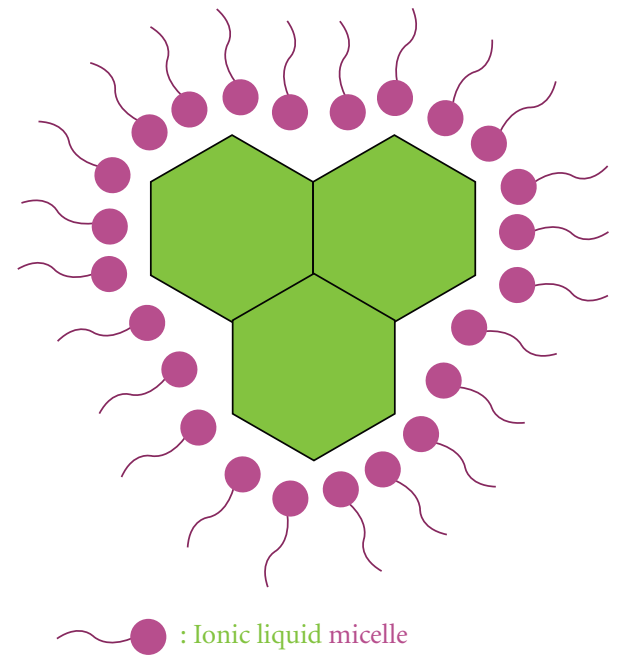

Scheme 2: Ionic liquid Micelle.

as nanoporous films with new phases and orientations. Synthesized ionic liquid [ADPPY] $[\mathrm{OH}$ ] plays dual role in entire system as micelle as shown in Scheme 2 which acts as interfacial surfactant. The basic nature of IL ( $\mathrm{pH} 10.7)$ successively replaces the external basic buffers. Synthesized IL exhibits intrinsic properties due to its green nature. Primary and secondary hydroxyl group of IL enhance the basicity and structural property. The reusability of IL successively replaces the conventional buffers. IL also plays the role as amphiphile of template for $\mathrm{ZnO}$ nanostructure tailoring.

The hydrogen group of aminopyridine moiety hence is constructing partial $\mathrm{O}-\mathrm{H}$ bonding with oxygen atom of $\mathrm{ZnO}$. Due to this bonding, the growth rate slightly decreases but enough to grow along (101) plane, which leads to form nanoflex, but the arrangement of nanoflex is exhibiting honeycomb-like construction.

3.1. XRD. XRD pattern of electrodeposited $\mathrm{ZnO}$ at 5 and 10 minutes deposition time exhibited that crystals are oriented along the (101) diffraction plane (Figure 1), which confirms the formation of pure $\mathrm{ZnO}$ with the hexagonal crystal structure, correspondance with JCPDS (card number 751533).

3.2. SEM. SEM image of scanning electron microscopy images of 10 minutes deposition time of $\mathrm{ZnO}$ thin film deposited on ITO substrate at different magnification are shown in Figure 2(a). The film is porous and well covered with overgrown particles on substrate. This overgrowth can be attributed to a nucleation and coalescence process. The surface morphology at 10,000 magnification (Figure 2(b)) is seen to be well covered, interconnected, microporous, and honeycomb like structure. The flake nanoparticle- and nanorods-like morphologies lead to high specific surface area and porous volume. An enlarged image (Figure 2(c)) clearly<smiles></smiles><smiles></smiles><smiles>OCC(O)C[n+]1ccc(N2[CH]O[Te]C2)cc1</smiles><smiles></smiles>

SCHeme 3: ZnO-IL-coordination.

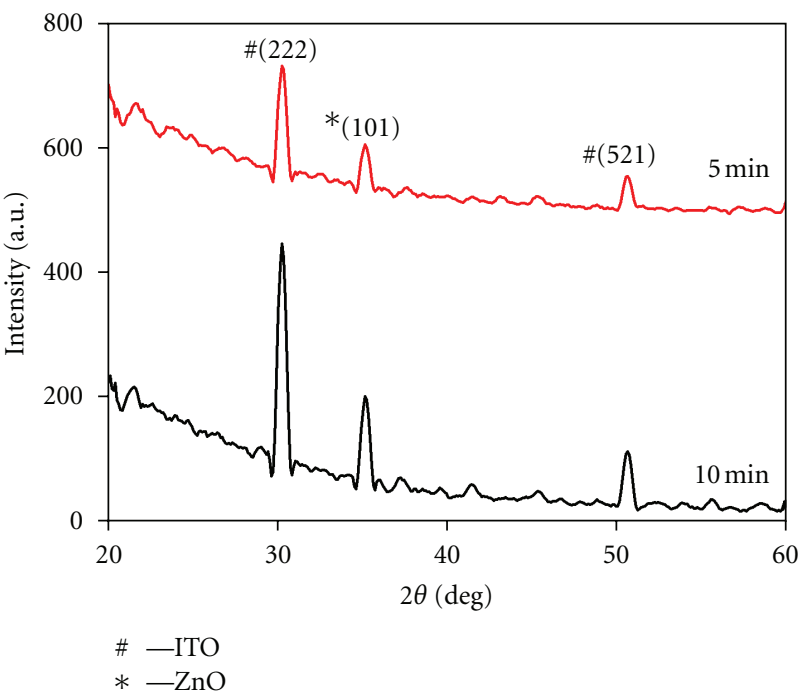

FIGURE 1: X-ray diffraction patterns of $\mathrm{ZnO}$ thin film at 5 and 10 minutes deposition time.

shows that the hallow nature of porous structure with wall thickness of 75-150 nm and pore diameter of 90-200 nm. The porous structure can be explained by interpenetrating network formation, similar to electrodeposited tungsten oxide thin films [36]. Zinc deposition is companied by hydrogen evolution at such negative potential in aqueous solution. Therefore, tiny hydrogen bubbles evolved during zinc deposition pores leads to porosity.

Wettability is a very important property governed by both the chemical composition and the geometrical structure 


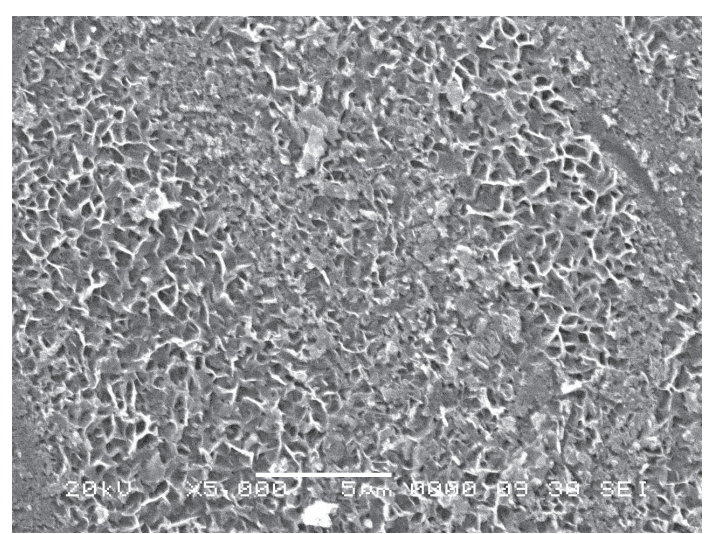

(a)

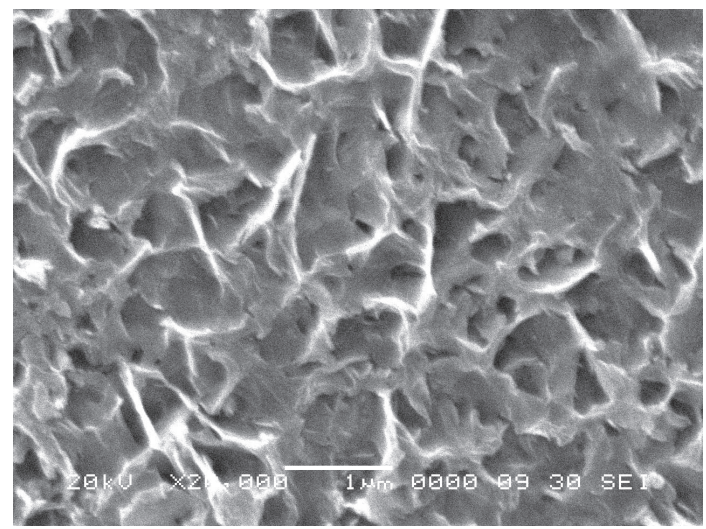

(c)

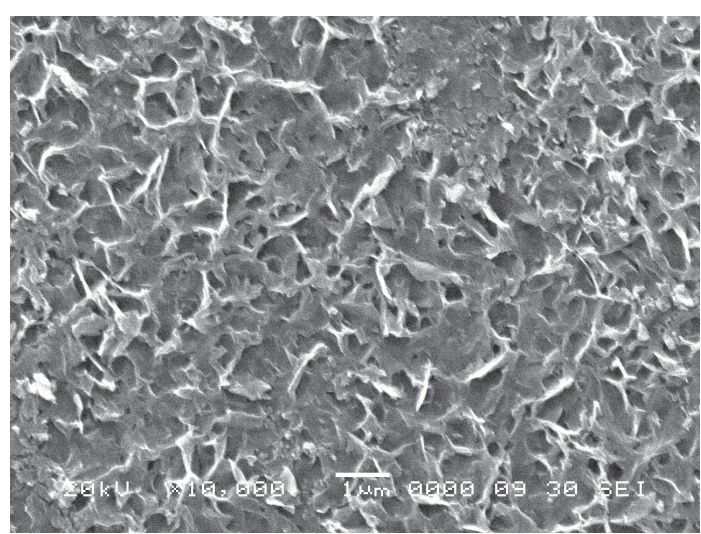

(b)

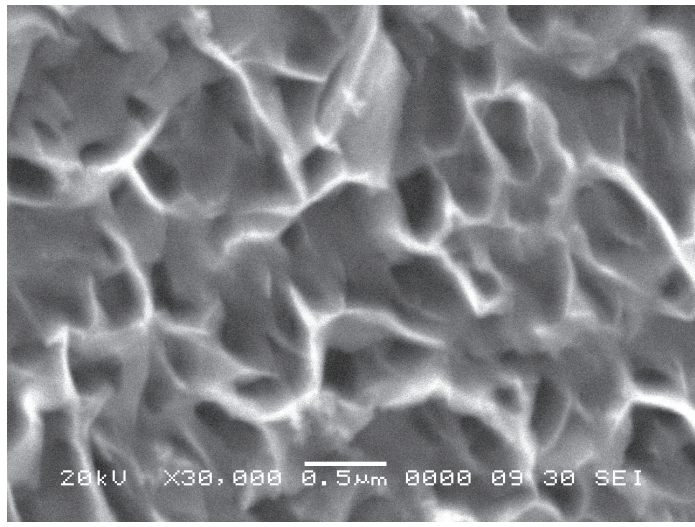

(d)

Figure 2: Scanning electron microscopy images at 10 minutes deposition time of ZnO thin film (a) 5000 magnification, (b) 10000 magnification, (c) 20000 magnification, and (d) 30000 magnification.

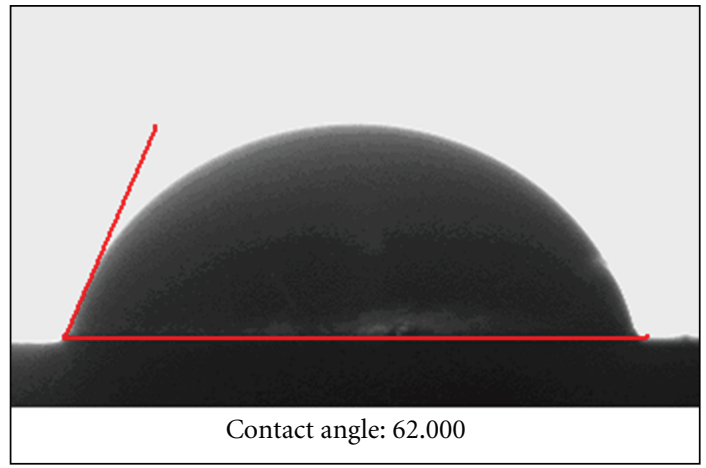

Figure 3: Static water contact angle of $\mathrm{ZnO}$ thin film.

of solid surfaces [37]. With the development of smart devices, such as intelligent microfluidic switch, reversibly controlling the surface wettability has aroused great interest and been realized by modifying the surface with stimuliresponsive organic compounds [38]. The wetting behavior of surfaces is governed by both their chemical composition and geometric microstructure. Latthe et al. investigated the effect of morphology and porous nature on the static water contact angle of the thin films [39]. The influence of the surface microstructure on the wetting property of air-dried

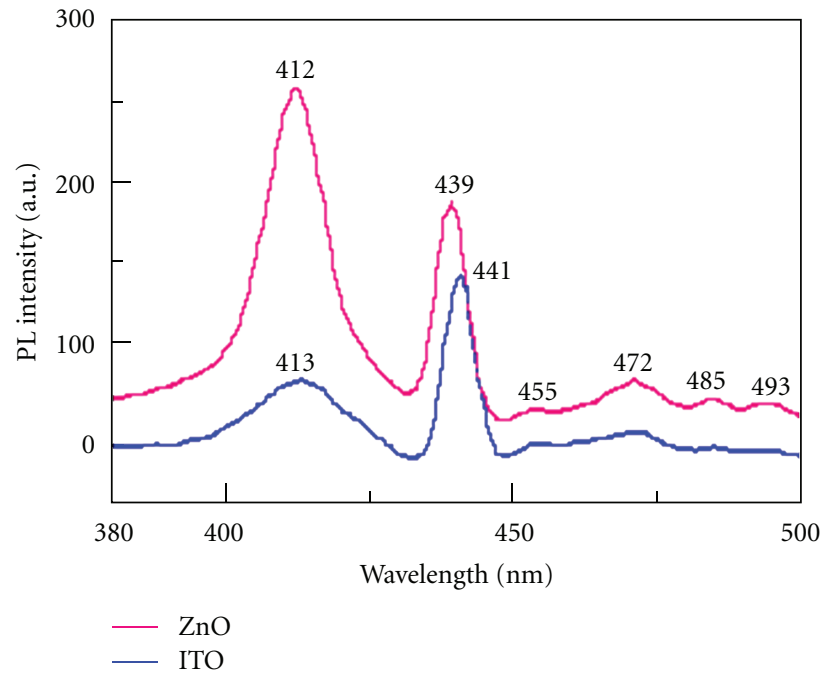

FIgURE 4: Room temperatures photoluminescence spectrum of $\mathrm{ZnO}$ thin film.

$\mathrm{ZnO}$ thin film was observed by measuring the static water contact angle. The static water contact angle of $\mathrm{ZnO}$ thin film was observed to be $62^{\circ} \mathrm{C}$, which indicates the hydrophilic nature of thin film (Figure 3). The wettability of any solid 


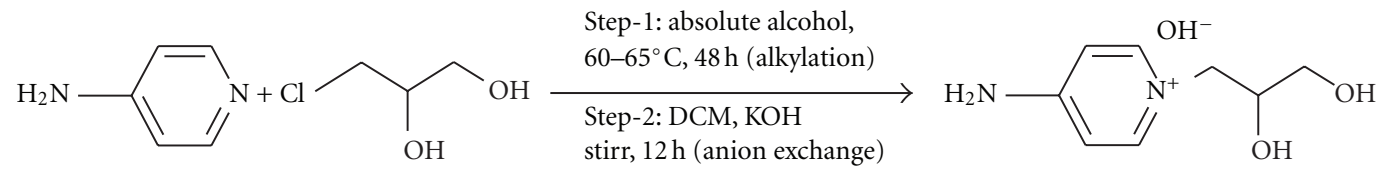

Figure 5

surface by a liquid increases with its porosity and it decreases the contact angle.

Zinc Oxide $(\mathrm{ZnO})$ can emit three luminescence bands in the ultraviolet (UV), green, and yellow regions. The strong emission is due the direct recombination of photogenerated charge carriers. The relatively weak UV emission is due to the defects that may trap the photogenerated holes or electrons $[12,40]$. The presence of defects in crystal is important for application in optoelectronics devices [41]. In the present case, visible light range 412 and $439 \mathrm{~nm}$ strong emission occurs, and with weak peak centered at about 455, 472, 485, $493 \mathrm{~nm}$. The PL peak from the ITO layer is situated at 413, $441 \mathrm{~nm}$ with wider full width of half maximum as shown in Figure 4. Strong peak is observed at 412, $439 \mathrm{~nm}$ due to blue emission of the $\mathrm{ZnO}$ thin film Which is similar to the earlier reported by chemical vapour deposition method [42]. Because there is no any evidence for the existence of cubic $\mathrm{ZnO}$ from XRD analysis of the thin film, this result indicates that the PL peak position of $\mathrm{ZnO}$ thin film on ITO glass substrate depends on the excitation intensity and could be adjusted by the PL from ITO buffer layer. The shifting of the peak towards lower wavelength increasing the peak intensity from ITO substrate is due to thin layer of $\mathrm{ZnO}$ nanostructure on ITO substrate.

\section{Conclusion}

In conclusion, $\mathrm{ZnO}$ thin films with porous morphology were electrosynthesized at room tempatures on ITO-coated glass substrate. Newly synthesized dihydroxylated ionic liquid based on 4-aminopyridinium cation and hydroxyl anion simultaneously acts as an electrolyte and surfactant. XRD pattern confirms crystal orientation along the (101) diffraction plane of pure $\mathrm{ZnO}$ with the hexagonal structure. The water contact angle measurements and PL result indicate that film is suitable for the device application, and ionic liquid is a suitable electrolyte and interfacial surfactant templating to develop greener protocol for electrochemical tailoringof thin film for technological application.

\section{Acknowledgment}

One of the author (B. G. Pawar) acknowledges the Department of Atomic Energy, Board of Atomic Research in Nuclear Science (Grant Sanction No-2008/36/83/-BRNS/4009) Government of India. The authors are also grateful to University Grants Commission, New Delhi, and Department of Science and Technology, Government of India for SAP and DSTFIST programme facilities.

\section{References}

[1] H. Weingrtner, "Understanding ionic liquids at the molecular level: facts, problems, and controversies," Angewandte Chemie International Edition, vol. 47, no. 4, pp. 654-670, 2008.

[2] D. Wei, S. J. Wakehamb, T. W. Ng, M. J. Thwaites, H. Brown, and P. Beecher, "Transparent, flexible and solid-state supercapacitors based on room temperature ionic liquid gel," Electrochemistry Communications, vol. 11, no. 12, pp. 2285-2287, 2009.

[3] R. Wahab, S. G. Ansari, Y. S. Kim et al., "Low temperature solution synthesis and characterization of $\mathrm{ZnO}$ nano-flowers," Materials Research Bulletin, vol. 42, no. 9, pp. 1640-1648, 2007.

[4] D. G. Tong, P. Wu, P. K. Su, D. Q. Wang, and H. Y. Tian, "Preparation of zinc oxide nanospheres by solution plasma process and their optical property, photocatalytic and antibacterial activities," Materials Letters, vol. 70, pp. 94-97, 2012.

[5] A. Kajbafvala, H. Ghorbani, A. Paravar, J. P. Samberg, E. Kajbafvala, and S. K. Sadrnezhaad, "Effects of morphology on photocatalytic performance of Zinc oxide nanostructures synthesized by rapid microwave irradiation methods," Superlattices and Microstructures, vol. 51, no. 4, pp. 512-522, 2012.

[6] A. Moezzi, A. M. Donagh, and M. B. Cortie, "Zinc oxide particles: synthesis, properties and applications," Chemical Engineering Journal, vol. 185-186, pp. 1-22, 2012.

[7] R. Wahab, I. H. Hwang, Y. S. Kim, and H. S. Shin, "Photocatalytic activity of zinc oxide micro-flowers synthesized via solution method," Chemical Engineering Journal, vol. 168, no. 1, pp. 359-366, 2011.

[8] S. Chakraborty, A. K. Kole, and P. Kumbhakar, "Room temperature chemical synthesis of flower-like $\mathrm{ZnO}$ nanostructures," Materials Letters, vol. 67, no. 1, pp. 362-364, 2012.

[9] H. Usui J, "Influence of surfactant micelles on morphology and photoluminescence of zinc oxide nanorods prepared by one-step chemical synthesis in aqueous solution," The Journal of Physical Chemistry C, vol. 111, no. 26, pp. 9060-9065, 2007.

[10] B. Wacogne, M. P. Roe, T. A. Pattinson, and C. N. Pannell, "In situ measurement of zinc oxide film thickness and optical losses," Applied Physics Letters, vol. 67, no. 2, pp. 161-163, 1995.

[11] B. Ismail, M. Abaab, and B. Rezig, "Structural and electrical properties of $\mathrm{ZnO}$ films prepared by screen printing technique," Thin Solid Films, vol. 383, no. 1-2, pp. 92-94, 2001.

[12] T. Mitsuya, S. Ona, and K. J. Wasa, "Structures and SAW properties of rf-sputtered single-crystal films of $\mathrm{ZnO}$ on sapphire," Journal of Applied Physics, vol. 51, no. 5, Article ID 2464, 7 pages, 1980.

[13] T. Ikeda, J. Sato, and Y. Hayashi, "Surface microstructures of $\mathrm{ZnO}$ coated $\mathrm{SnO}_{2}$ : F films," Solar Energy Materials and Solar Cells, vol. 34, no. 1-4, pp. 379-384, 1994.

[14] J. S. Kim, H. A. Marzouk, P. J. Reocroft, and C. E. Hamrin, "Characterization of high quality $\mathrm{c}$ axis oriented $\mathrm{ZnO}$ thin films grown by metal organic chemical vapor deposition using zinc acetate as source material," Thin Solid Films, vol. 217, no. 1-2, pp. 133-137, 1992. 
[15] P. Bonasewicz, W. Hirschwald, and G. Neumann, "Conductivity-controlled preparation of $\mathrm{ZnO}$ films with high electrical resistance," Thin Solid Films, vol. 142, no. 1, pp. 77-82, 1986.

[16] S. H. Jeong, B. S. Kim, and B. T. Lee, "Photoluminescence dependence of $\mathrm{ZnO}$ films grown on $\mathrm{Si}(100)$ by radiofrequency magnetron sputtering on the growth ambient," Applied Physics Letters, vol. 82, no. 16, Article ID 2625, 3 pages, 2003.

[17] X. L. Wu, G. G. Siu, C. L. Fu, and H. C. Ong, "Photoluminescence and cathodoluminescence studies of stoichiometric and oxygen-deficient ZnO films," Applied Physics Letters, vol. 78, no. 16, Article ID 2285, 3 pages, 2001.

[18] A. Kuroyanagi, "Properties of aluminum-doped $\mathrm{ZnO}$ thin films grown by electron beam evaporation," Japanese Journal of Applied Physics, vol. 28, pp. 219-222, 1989.

[19] M. G. Ambia, M. N. Islam, and M. O. Hakim, "The effects of deposition variables on the spray pyrolysis of $\mathrm{ZnO}$ thin film," Journal of Materials Science, vol. 29, no. 24, pp. 6575-6580, 1994.

[20] M. Guoa, C. Y. Yang, M. Zhang et al., "Effects of preparing conditions on the electrodeposition of well-aligned $\mathrm{ZnO}$ nanorod arrays," Electrochimica Acta, vol. 53, no. 14, pp. 46334641, 2008.

[21] H. Y. Jing, X. L. Li, Y. Lu, Z. H. Mai, and M. Li, "Electrochemical self-assembly of highly oriented $\mathrm{ZnO}$-surfactant hybrid multilayers," The Journal of Physical Chemistry B, vol. 109, no. 7, pp. 2881-2884, 2005.

[22] J. Qiu, M. Guo, and X. Wang, "Electrodeposition of hierarchical $\mathrm{ZnO}$ nanorod-nanosheet structures and their applications in dye-sensitized solar cells," ACS Applied Materials \& Interfaces, vol. 3, no. 7, pp. 2358-2367, 2011.

[23] A. C. Cruickshank, S. R. Tay, B. N. Illy et al., "Electrodeposition of $\mathrm{ZnO}$ nanostructures on molecular thin films," Chemistry of Materials, vol. 23, no. 17, pp. 3863-3870, 2011.

[24] L. Xu Q, Chen, and D. Xu J, "Hierarchical ZnO nanostructures obtained by electrodeposition," The Journal of Physical Chemistry C, vol. 111, no. 31, pp. 11560-11565, 2007.

[25] T. Yoshida, D. Komatsu, N. Shimokawa, and H. Minoura, "Mechanism of cathodic electrodeposition of zinc oxide thin films from aqueous zinc nitrate baths," Thin Solid Films, vol. 451-452, pp. 166-169, 2004.

[26] L. Xu, Y. Guo, Q. Liao, J. Zhang, and D. Xu, "Morphological control of $\mathrm{ZnO}$ nanostructures by electrodeposition," Journal of Physical Chemistry B, vol. 109, no. 28, pp. 13519-13522, 2005.

[27] A. I. Inamdar, S. H. Mujawar, S. B. Sadale et al., "Electrodeposited zinc oxide thin films: nucleation and growth mechanism," Solar Energy Materials and Solar Cells, vol. 91, no. 10, pp. 864-870, 2007.

[28] C. Boeckler, T. Oekermann, A. Feldhoff, and M. Wark, "Role of the critical micelle concentration in the electrochemical deposition of nanostructured $\mathrm{ZnO}$ films under utilization of amphiphilic molecules," Langmuir, vol. 22, no. 22, pp. 94279430, 2006.

[29] K. S. Choi, H. C. Lichtenegger, G. D. Stucky, and E. W. McFarland, "Electrochemical synthesis of nanostructured $\mathrm{ZnO}$ films utilizing self-assembly of surfactant molecules at solid-liquid interfaces," Journal of the American Chemical Society, vol. 124, no. 42, pp. 12402-12403, 2002.

[30] Y. Tan, E. M. P. Steinmiller, and K. S. Choi, "Electrochemical tailoring of lamellar-structured $\mathrm{ZnO}$ films by interfacial surfactant templating," Langmuir, vol. 21, no. 21, pp. 96189624, 2005.
[31] P. P. Salvi, A. M. Mandhare, A. S. Sartape, D. K. Pawar, S. H. Han, and S. S. Kolekar, "An efficient protocol for synthesis of tetrahydrobenzo[ $b]$ pyrans using amino functionalized ionic liquid," Comptes Rendus Chimie, vol. 14, no. 10, pp. 878-882, 2011.

[32] S. Manne, J. P. Cleveland, H. E. Gaub, G. D. Stucky, and P. K. Hansma, "Direct visualization of surfactant hemimicelles by force microscopy of the electrical double layer," Langmuir, vol. 10, no. 12, pp. 4409-4413, 1994.

[33] J. F. Liu and W. A. Ducker, "Surface-induced phase behavior of alkyltrimethylammonium bromide surfactants adsorbed to mica, silica, and graphite," Journal of Physical Chemistry B, vol. 103, no. 40, pp. 8558-8567, 1999.

[34] A. Goux, T. Pauporté, J. Chivot, and D. Lincot, “Temperature effects on $\mathrm{ZnO}$ electrodeposition," Electrochimica Acta, vol. 50, no. 11, pp. 2239-2248, 2005.

[35] H. Philippe and L. Corinne, "Electrochemical reactivity in room-temperature ionic liquids," Chemical Reviews, vol. 108, no. 7, pp. 2238-2264, 2008.

[36] P. Shen, N. Chi, and K. Y. Chan, "Morphology of electrodeposited $\mathrm{WO}_{3}$ studied by atomic force microscopy," Journal of Materials Chemistry, vol. 10, pp. 697-700, 2000.

[37] A. B. D. Cassie and S. Baxter, "Wettability of porous surfaces," Transactions of the Faraday Society, vol. 40, pp. 546-551, 1944.

[38] K. Ichimura, S. K. Oh, and M. Nakagawa, "Light-driven motion of liquids on a photoresponsive surface," Science, vol. 288, no. 5471, pp. 1624-1626, 2000.

[39] S. S. Latthe, H. Imai, V. Ganesan, and A. V. Rao, "Superhydrophobic silica films by sol-gel co-precursor method," Applied Surface Science, vol. 256, no. 1, pp. 217-222, 2009.

[40] Y. F. Gao, M. Nagai, Y. Masuda, F. Sato, and K. Koumoto, "Electrochemical deposition of $\mathrm{ZnO}$ film and its photoluminescence properties," Journal of Crystal Growth, vol. 286, no. 2, pp. 445-450, 2006.

[41] B. G. Pawar, D. V. Pinjari, S. S. Kolekar, A. B. Pandit, and S. H. Han, "Effect of sintering temperatures on the synthesis of $\mathrm{SnO}_{2}$ nanospheres," ISRN Chemical Engineering, vol. 2012, Article ID 954869, 7 pages, 2012.

[42] T. Sekiguchi, K. Haga, and K. Inaba, "ZnO films grown under the oxygen-rich condition," Journal of Crystal Growth, vol. 214, pp. $68-71,2000$. 

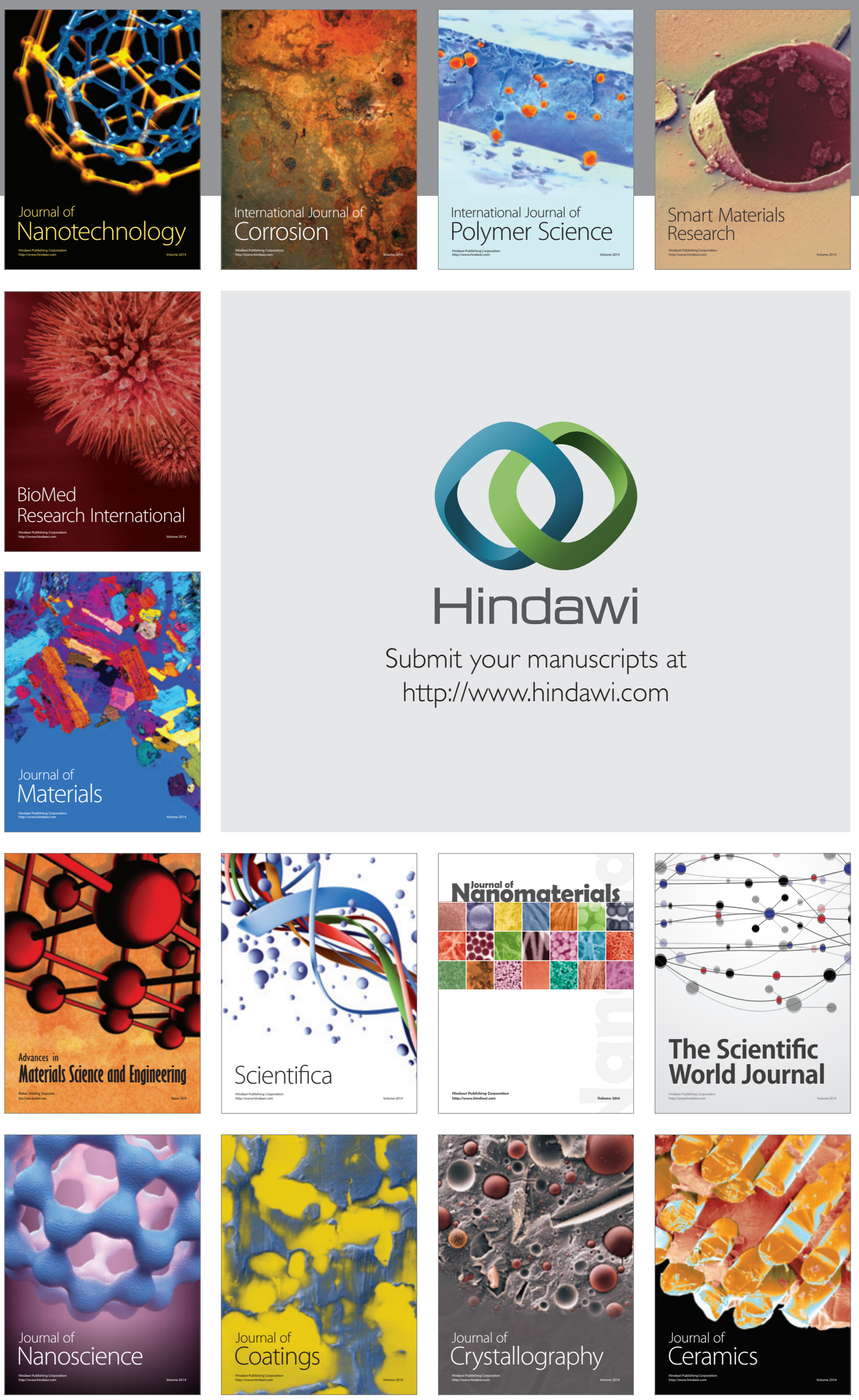

The Scientific World Journal

Submit your manuscripts at

http://www.hindawi.com

\section{World Journal}

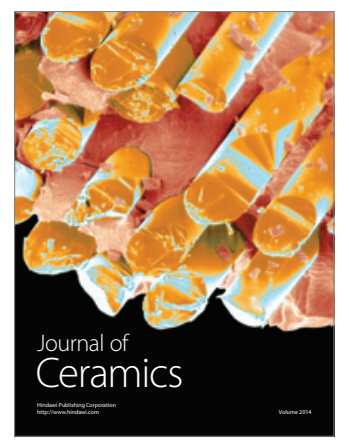

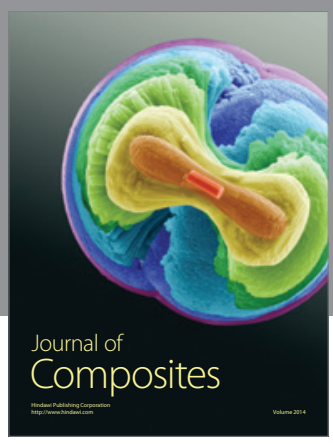
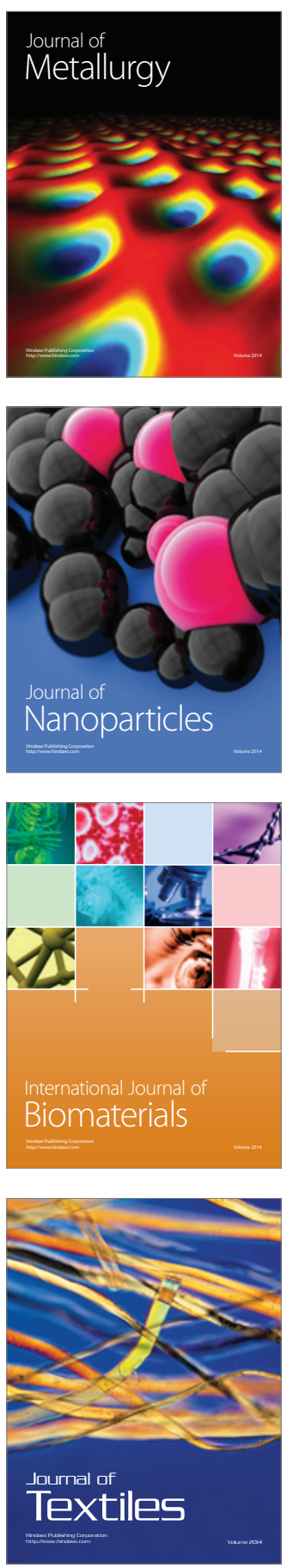